\title{
MOVIMENTO INTERIORIZANTE E ASCENSIONAL NO DE QUANTITATE ANIMAE DE AGOSTINHO
}

\author{
Yara Miris de Medeiros Trevisan ${ }^{1}$ \\ Università degli Studi di Padova
}

Resumo: 0 presente trabalho pretende abordar o diálogo de Agostinho intitulado De quantitate animae ou A grandeza da alma. Examinamos a alma observando a origem, natureza e potencialidades. 0 artigo apresenta os sete graus de atividade da alma em um movimento que ao mesmo tempo é interior e ascensional, pois a partir do conhecimento da alma, isto é, do conhecimento de si, que conhecemos Deus. É a partir da insuficiência de cada grau que a alma galgará a outro na busca de seu Criador, pois está inquieta em conhecer e contemplar Deus. A alma é um dos temas mais relevantes do pensamento agostiniano e, no entanto pouco abordado. Sua relevância está na impossibilidade de explicar o propósito e a finalidade da criação do homem sem apontar, tal como Agostinho, a natureza daquilo que faz o humano semelhante a Deus: a alma. Analisamos a partir do diálogo De quantitate animae que nasceu das dúvidas de Evódio em 387, o que não quer dizer, em absoluto, que outras obras do pensador não tenham sido consultadas e utilizadas. Apresentamos, então, a origem, natureza e qualidades, potencialidades e os sete graus de atividade da alma humana. Se no diálogo é importante falar da natureza e substância da alma, é mais significativo ainda explicar os seus graus ascensionais, os quais a alma pode alçar a fim de conhecer-se e encontrar-se com quem tanto almeja. Essa ânsia do homem em conhecer Deus, e consequentemente a si, desperta um movimento que na alma implica o modo como se realiza o conhecimento, o qual chamamos movimento de interiorização e ascensão. Temos o objetivo de apresentar o itinerário agostiniano para Deus a partir de suas reflexões sobre a alma e de como se dá 0 conhecimento. 0 conhecer agostiniano é por etapas, por graus que vão diretamente para Deus. 0 artigo trata do percurso que a alma pode traçar em busca do conhecimento de seu Criador por meio do conhecimento de si mesma. Examinamos a alma observando a origem, natureza e potencialidades. A esse itinerário Agostinho chamará de sete graus de atividade da alma, mais especificamente da alma humana, pois os vegetais e os animais não possuem razão e por isso não podem inteligir Deus. 0 percurso parte da alma inerte, passa pela alma que se converte, se purifica, até chegar ao conhecimento da Verdade. No entanto, é preciso dizer que a alma passará pelos graus que são próprios do homem com a ajuda divina, pois é insuficiente em si mesma para buscar a Deus, limpar-se e permanecer limpa, isto é, apta ao conhecimento e contemplação de seu Criador.

Palavras-chave: Alma. Conhecimento. Busca. Imaterialidade. Deus.

\footnotetext{
${ }^{1}$ Mestranda em Filosofia. E-mail: yaramiris.demedeirostrevisan@studenti.unipd.it
} 
Yara Miris de Medeiros Trevisan

\title{
The interiorizing and upward movement in Augustine's De Quantitate Animae
}

\begin{abstract}
The present work intends to approach the Augustine's dialogue titled De quantitate animae or The measure of soul. We analyzed the soul observing the origin, nature, and potencialities. The work culminates in the seven degrees of soul activity, in a move whereby - because of the soul knowledge, i.e. the knowledge we know God - it is inside and climbing withal. From the insufficiency of each degree, the soul rises to another degree seeking its creator; it is restless to know and contemplate its God. The soul is one of the most relevant themes in St. Augustine thought yet little addressed. It is never possible explain the purpose and finality of man creation without pointing out, as Augustine had done, the nature of what makes the human similar to God: the soul. We analyzed it from the De quantitate animae or The magnitude of the Soul, which was born of the Evodius' doubts in 387, but it does not mean that other Augustine's works were not consulted or used. Then, we show the origin, nature and qualities, potentialities and the seven degrees of human soul activity. If in the foregoing dialogue it is important to address the nature and substance of the soul, it is even more significant to explain their ascending degrees, which the soul can reach in order to know itself and meet with the one it desires so much. This man's longing to know God and, consequently, himself, awakens a movement that, in the soul, implies the way in which knowledge is realized, which we call interiorization and ascention movement. The objective of this work is to present the Augustinian's path unto God, from this author's reflections on soul and on the way knowledge is developed. The Augustinian's way to know is composed by steps, by degrees that go directly to God. This article deals with the route the soul can follow so as to know its Creator by means of the knowledge of itself. During the writing of this work, we faced a lack of state-of-the-art in terms of works about De quantitate Animae, especially in Portuguese. Such works that we found out were written in Italian originally and so then translated. Augustinian knowledge stages split up by degrees which drive directly to God. Augustine calls them seven-degree activity of the soul, nay of the human soul, given that plants and animals cannot understand God for having no rationality. The path begins from the inert soul, goes through the soul that converts and purifies itself, until reaches the knowledge of Truth. The soul goes through the degrees that are properly human with the divine aid, because of its insufficiency to seek God, cleanse itself and remain clean, i.e., apt to the knowledge and contemplation of its Creator.
\end{abstract}

Keywords: Soul. Knowledge. Seeking. Immateriality. God. 
A expressão quantitate no diálogo, em primeira análise, é traduzida por quantidade; tão grande. Podemos pensar quantidade como aquilo que pode ser medido, mensurado, quantificado. Entretanto, Agostinho deixa claro logo na primeira parte do livro que a alma não tem dimensões físicas como tamanho, largura ou extensão, ou seja, não pode ser medida e nisso consiste sua grandeza, pois o que pode ser mensurado ou aquilo que é físico, como o corpo, é corruptível e a alma, por não ter forma física, tem sua substancialidade inalterada.

Na introdução de La Grandezza Dell'anima Pascucci diz que a obra se concentra na quantitas, vocábulo inusitado se referido à alma, mas que na verdade inclui os termos que Agostinho individualizou como essenciais de seu problema de sempre, da identidade e da salvação do homem. De fato é justamente da análise do quantitas que emergirá a não quantitas da alma e a sua verdadeira grandeza. ${ }^{2}$

Examinando o que a alma não é Agostinho procura apontar o que a alma é, pois a alma não sendo física não pode ser medida, logo, será justamente do julgamento daquilo que pode ser mensurado, o corpo, que falará sobre o que não pode, a alma. Dessa forma, dizemos que ao invés de o que se pode medir, quantitate é aquilo que se pode falar a respeito da alma. Pois não se trata absolutamente de mostrar extensões, mas de refletir a alma filosoficamente.

0 diálogo De quantitate animae Consiste em duas partes. A primeira, a qual não trataremos aqui se inicia em I, 1 e vai até XXXII, 69, e a segunda, tema deste artigo, compreende 0

\footnotetext{
2 'L'opera si concentra sulla anima quantitas, vocabolo inusitato se riferito all'anima ma che in realtà include i termini che Agostino ha individuato come essenziali del suo problema di sempre, dell'identità e della salvezza dell'uomo. Infatti è proprio dall'analisi della quantitas che emergerà la non quantitas dell'anima e la sua vera grandezza." (AGOSTINO. La grandezza dell'anima. Tradução de Paola Pascucci. Roma: Città Nuova. 2009, p. 18) Traduzido livremente.
} 
trecho XXXIII, 70-76 que considera a grandeza da alma nos seus sete graus de atividade. 0 ponto central da primeira parte do diálogo são as dúvidas de Evódio acerca da alma humana, são elas: sua origem, suas qualidades, sua grandeza, a razão de sua presença no corpo, as transformações que sofre quando se une ao corpo e quando remove-se dele ${ }^{3}$. Agostinho trata das três primeiras questões, introduz os graus da alma e encerra o diálogo, deixando as outras dúvidas de seu amigo para um próximo encontro. 0 motivo pelo qual Evódio deseja saber mais sobre este tema é porque acredita que o conhecimento da alma é conhecimento de si.

Como já anunciado, trataremos da segunda parte do diálogo, sobre os graus da alma, de como traçará seu caminho em direção ao Criador. 0 caminho é o conhecimento de si. Nessa acepção, conhecer tem o sentido de reconhecer, isto é, o homem vê em si aquilo que desde muito antes já se encontrava impresso em seu interior.

$\mathrm{Na}$ ausência desse reconhecimento a alma volta a si mesma, busca o conhecimento deparando-se como criatura. Nisso vê-se impulsionada a conhecer Deus aquietando-se em sua contemplação. Porém, esse estado não implica a perfeição, visto que perfeito é somente o Criador.

Duas questões lhe dizem respeito: uma concernente à alma, outra a Deus. A primeira faz com que nos conheçamos a nós mesmos, a segunda leva-nos ao conhecimento de nossa origem. A primeira nos é mais agradável, a segunda mais cara; a primeira nos torna dignos da vida feliz, a segunda nos torna felizes; a primeira é para os que aprendem aquelas coisas, a segunda é para os já instruídos. Este é o método dos estudos da sabedoria, pelo qual alguém se capacita a entender a ordem das coisas, isto é, a conhecer os dois mundos e 0

\footnotetext{
3 "Da dove l'anima derivi; quali siano i suoi attributi; quanto sia grande; perché sia stata data al corpo; quali transformazioni subisca una volta che sia giunta nel corpo e una volta che se ne sia allontanata." (AGOSTINO. Sull'anima (L'immortalità dell'anima. La grandezza dell'anima). Tradução e notas de Giovanni Catapano. Milano: Bompiani . 2003, p. 123)
} 
próprio Pai do universo, do qual não há nenhum conhecimento na alma a não ser saber até que ponto o desconhece. (AGOSTINHO, 2008, p 245-6)

Há dois problemas de mais relevância na filosofia agostiniana: a alma e Deus ${ }^{4}$. Por isso vai buscar o conhecimento de ambos, aliás é o que deseja conhecer mais ardentemente. Para Agostinho compreender a alma nos proporciona conhecer a nós mesmos e Deus. No entanto, esse conhecimento de si é construído, se adquire por meio da busca, ou, como diz Agostinho no De quantitate Animae, por meio dos sete graus que a alma pode percorrer, e esse entendimento de si é o que possibilita à alma o conhecimento de Deus.

0 método da sabedoria é o conhecimento pleno de si e de Deus. Porém, a alma enquanto desprovida do conhecimento de Deus está vazia, inquieta, pois o único conhecimento que tem é que Deus the é desconhecido.

Carente de plenitude, na ausência do conhecimento de Deus, o homem torna-se peregrino em seu próprio existir. Impulsionado por essa falta percorre o caminho até seu Criador. Esse percurso sugere mais que um retorno, é um encontro não apenas com a fonte de vida, mas com a própria Vida. Na vida inquieta do ser humano está pressuposta não somente a necessidade de quietude, como também a possibilidade de alcançar a plenitude. Como dirá Agostinho, a parte interior do homem, sua alma, é aquela que procurará Deus, uma vez que o caminho possível ao corpo de percorrer, o de sensações, é insuficiente para tal propósito (AGOSTINHO, 2004, 449-451).

\footnotetext{
${ }^{4}$ No diálogo com a Razão nos Solilóquios Livro I, II, 7 Agostinho expressa seu desejo: "R. Então, o que desejas saber? - Tudo o que pedi na oração. - Faze um breve resumo de tudo. - Desejo conhecer a Deus e a alma. - Nada mais? - Absolutamente nada.
} 
Yara Miris de Medeiros Trevisan

A alma é a realidade mais íntima do homem interior. É melhor que o corpo, pois somente ela pode conhecer a verdade. 0 movimento interiorizante da alma é aquele que leva a Deus, é dentro e não fora do homem que Deus habita. Logo, buscar por Deus no exterior das criaturas é vão porque Deus não está fora, mas sim dentro. ${ }^{5}$

0 filósofo deseja, então, conhecer a alma e Deus. Não somente Deus porque Deus está no íntimo do homem, na alma. Para chegar até Ele o homem precisa buscá-lo em seu interior. Assim, busca se conhecer e ao percebe-se pecador dá abertura a Deus.

Aquele que criou o homem e que nele pode atuar é o que o ser humano deve, em sua vida, ansiar conhecer. 0 conhecimento apenas da alma não basta para aquietar 0 coração. 0 homem só será feliz quando conhecer a si mesmo e a Deus. Até lá estará inquieto ${ }^{6}$ em busca de algo que, às vezes não sabe o que é, mas mesmo assim sente falta.

Essa ânsia do homem em conhecer Deus e consequentemente a si, desperta um movimento que na alma implica o modo como se realiza o conhecimento. A esse movimento denominamos sete graus da alma, de interiorização e ascensão.

Os graus traçam 0 itinerário da alma para Deus. 0 percurso parte da alma inerte, passa pela alma que se converte, se purifica, até chegar ao conhecimento da Verdade. No entanto, é preciso dizer que o homem busca a Deus porque Este o conduz a busca-lo. ${ }^{7}$

\footnotetext{
5 "E eis que estavas dentro de mim e eu fora, e aí te procurava, e eu, sem beleza, precipitava-me nessas coisas belas que tu fizeste" (AGOSTINHO, 2004, p 491).

6 "Ès tu que fazes com que ele se delicie em louver-te, porque tu nos fizeste para ti, e o nosso coração está inquieto enquanto não repousar em ti". (AGOSTINHO, 2004, p. 5)

7 "Almejo-te; e novamente te peço aquilo que se necessita para almejar-te. Perece aquele a quem abandonas, porque és o bem supremo a quem não deixa de encontrar aquele que procura corretamente. E procura corretamente todo aquele a quem conduzes para que procurem corretamente" (AGOSTINHHO, 2007, p 20)
} 
Agostinho, antes de expor os sete graus, fala a Evódio para não se entusiasmar ou pensar que falará vastamente sobre todas as almas; vai apresentar as atividades da alma humana racional, não se aterá às almas dos vegetais e dos animais. Sua pretensão é mostrar o caminho que a alma deve percorrer, ou seja, de fora para dentro e de dentro para mais dentro em sentido ascendente e não tratar longamente sobre os princípios vegetativos e sensitivos descritos no primeiro e segundo graus.

0 primeiro grau da alma, ou ação sobre o corpo, comum aos homens, aos animais e às plantas tem como objetivo a manutenção do corpo. É responsável pela distribuição de fontes de energia; cuida da harmonia e cooperação entre os órgãos do corpo.

A alma humana dá vida a este corpo terreno e mortal com sua presença, dá-lhe unidade e o conserva na unidade, não lhe permite desagregar-se e diluir-se, faz com que 0 alimento se distribua de modo uniforme a todos os membros, fornece a cada um o que é seu, preserva sua harmonia e proporção, não somente quanto à beleza, mas também quanto ao crescimento e à procriação (AGOSTINHO, 2008, p 339).

Neste estágio é próprio da alma conferir vida ao corpo. No entanto, a alma está inerte no conhecimento de si e na busca do conhecimento de seu Criador, pois se atém a atividade de animar o corpo uma vez que seu movimento se direciona ao que é físico, corpóreo, orgânico. 0 primeiro grau corresponde às necessidades fisiológicas.

A verdadeira grandeza da alma encontra-se nela mesma, de modo que seu valor está no que ela pode fazer. Nesse grau a alma se atém a imanência, ela vivifica o corpo.

\section{Blucher}


No segundo grau ou pelo corpo faz referência à alma sensitiva, aquela que por meio dos sentidos percebe 0 que lhe afeta. 0 corpo e a alma a partir daqui estabelecem entre si uma unidade, enquanto que no grau anterior o corpo se apresentava passivo, pois era apenas animado por ela sem lhe agregar algo, nesse grau assume a forma ativa já que sua relação com a alma se estreita. Na atividade anterior a alma dava vida a um corpo, nessa atividade está unida a ele, o qual proporciona sensações que não seriam experiênciadas pela alma de outro modo, senão por meio da corporeidade. Ora, a atividade da alma era somente a de animar (ela dava vida) e agora tem uma ação a mais, a de sentir. Neste grau dois elementos agem juntos, o corpo e a alma são igualmente atuantes.

Na criação de todos os seres, o homem é o ser mais perfeito. Nesse ato da alma excluemse os vegetais ou os seres fixados por raízes, visto que não possuem sentidos.

A alma se aplica ao tato e por ele sente e distingue o que é frio, áspero, liso, duro, leve, pesado. Além disso, discerne pelo paladar, pelo olfato, pela audição e pela visão as inúmeras diferenças de sabores, de odores, de sons, de formas. Em todas essas operações aceita e apetece o que for adequado à natureza de seu corpo; rejeita e evita o que é contrário. Retira-se dos sentidos por certo intervalo de tempo e, refazendo a atuação deles, como que tirando férias, revolve consigo atropelada e repetidamente as imagens das coisas que observou por meio deles; isso é o que constitui o sono e os sonhos. Às vezes, também, pela facilidade do movimento deleita-se saltando e vagueando e, sem esforço, ordem e harmonia dos membros; faz o que pode para a cópula dos sexos e, da natureza de dois, constrói um só ser pela comunhão e pelo amor. Concorre não somente para a geração dos fetos, mas também para incubá-los, protegê-los e alimentá-los. Liga-se por hábito às coisas entre as quais o corpo vive e com as quais se mantém, e dificilmente se separa delas, como se fossem membros. A força desse hábito que não se interrompe pela desunião das coisas e pelo decurso do tempo, denomina-se memória (AGOSTINHO, 2008, p 340).

\section{SOFiA Papers}

Guarulhos, v. 2, n. 2, 2018| ISSN: 2176-5960

Edition for the $11^{\text {th }}$ SOFIA at UNIFESP 
Estamos no segundo grau, no ato da alma por meio do corpo (sensação). Aqui se distinguem os objetos sensíveis, tais como duro e mole, quente e frio, doce e amargo, entre outras; nesse estágio a alma é responsável pelo movimento do corpo, sente o corpo, apreende o que os sentidos possibilitam. Assim, a alma, de um estado vegetativo alça a um estágio de apreensão.

Também nesse grau aparece a memória sensitiva, atributo dos homens e dos animais onde são guardadas as sensações proporcionadas pelo ambiente que os circundam. Além disso, faz o corpo interagir e tomar consciência de seus processos físico-químicos.

Enquanto a primeira atividade da alma está para a manutenção da vida e a segunda voltada às sensações do corpo, a terceira ou acerca do corpo, emprega intenção aos atos realizados; o homem agora não dotado apenas da memória sensitiva, faz-se instância criadora de arte, de técnica e de confecção de bens para sua vida ${ }^{8}$.

Esse grau, próprio do ser humano, está ligado à cultura, ao cultivo da vida humana, à civilização. Deixamos de lado os seres irracionais, pois segundo sua natureza não podem ir adiante como o homem, já que como sabemos os animais não transformam o meio onde vivem.

\footnotetext{
${ }^{8}$ Entendemos, neste grau, que o conceito de poíesis aristotélico é conhecido por Agostinho que teve acesso a obra de Aristóteles quando tinha aproximadamente vinte anos, conforme nos relata em suas Confissões (CATAPANO. In: Agostino, 2003, p. 24). Por poiesis entende-se "ação de fabricar, fabricação. Confecção de um objeto artesanal. Composição de uma obra poética. O verbo poíeo significa: fabricar, executar, confeccionar (obras manuais), compor (obras intelectuais como poema), construir, produzir (no trabalho agrícola), provocar (riso, doença, vergonha, pobreza, lágrimas, riqueza), fazer (sacrifícios aos deuses, a guerra, o bem ou o mal a alguém); agir com eficácia produzindo um resultado (um remédio, uma arma, um artefato). Aristóteles explicita o sentido principal da poíesis como uma prática na qual o agente e o resultado da ação estão separados ou são de natureza diferente. A poiesis liga-se à ideia de trabalho como fabricação, construção, composição e à ideia de téchne" (CHAUÍ, 1994, p. 358).
}

\section{Blucher}


A alma desenvolve cultura, arte, e todo tipo de produção intencional. Essa qualidade é atribuição somente da alma humana, os animais não aplicam intenções a seus atos, agem por impulso e não por razão ou intuito de realizar algo. Os humanos têm a possibilidade de não somente interagir com a sociedade na qual está inserido, como também agregar valor a esta por meio de suas ações e por meio do uso da razão.

Pensa na memória das inumeráveis coisas, das inveteradas pelo hábito, mas gravadas e retiradas pela reflexão e pelos sinais, em tantas obras de artistas, no cultivo dos campos, na construção de cidades, nas variedades maravilhosas de inúmeros edifícios e monumentos, na descoberta de tantos sinais e letras, nas palavras, nos gestos, no som de qualquer espécie, nas pinturas e esculturas, nas línguas de tantos povos, em tantas instituições, em tantas coisas novas, em tantas restauradas; pensa também no número elevado de livros, de monumentos para guarda da memória, na tão grande preocupação pela posteridade; nas categorias de ofícios, poderes, honras e dignidades, seja nas famílias, seja na república doméstica e da milícia, seja nas cerimônias sagradas ou profanas, no poder do raciocínio e da investigação, nos rios de eloquência, nas variedades de poesia, nos milhares de recursos para o divertimento e os jogos, na perícia da arte musical, na precisão das medidas, na ciência dos cálculos, na interpretação do passado e do futuro pelo presente. São grandes essas realidades e exclusivamente humanas. Mas ainda são comuns a doutos e rudes, a bons e maus (AGOSTINHO, 2008, p 341)

A alma estabelece relação entre as coisas através da intenção. 0 desejo ou intenção de fazer algo para si e para sua comunidade está presente. Se neste grau os animais estão excluídos 0 mesmo não acontece entre os homens, pois a alma racional é própria a todos os humanos, não distingue nenhum deles ou acerca deles não interessa, ainda, distinguir nenhum valor moral. Os homens tanto sábios como grosseiros têm o poder de produzir cultura, história. 
À medida que a alma ascende, os vegetais e os animais, por necessidade, vão sendo excluídos, ou seja, de um ponto de vista da Criação, cada ser toma seu lugar conforme sua natureza. Os vegetais, não ultrapassam a vegetalidade; os animais, sua animalidade; no entanto, com o ser humano ocorre que a alma pode alcançar o último ato, pode ascender. Contudo, não queremos dizer que ascenderá necessariamente, uma vez que para isso é necessário deliberar, recorrer ao livre-arbítrio.

No dispor do livre-arbítrio como se elevará a alma aos graus subsequentes? Ao perceber ser mais que um animal, que pode produzir grandes realidades, que pode inteligir; o homem vê a possibilidade de ir além, porém não é autossuficiente, ao perceber sua humanidade vislumbra a possibilidade de ascender ao próximo estágio, mas não o pode fazer sozinho, esse movimento necessita da ajuda divina.

Na alma humana está impressa a imagem da Perfeição. No quarto grau ela produz a ética e a moral, uma vez que "se atreve a se antepor não somente a seu corpo, se ele se considera uma parte do universo, mas também ao próprio universo" (AGOSTINHO, 2008, p. 341). Contudo, a ética e a moral por si mesmas não são suficientes, elas apenas indicam ao homem que ele é capaz de disciplinar suas vontades e continuar indo adiante. São tantas as contradições da vida humana que é necessário "considerar o trabalho e o grande conflito contra as adversidades e as seduções deste mundo" (Id. Ibidem), o homem sabe que pode tornar-se perfeito, mas que não pode sozinho. Busca a ajuda divina para sustentá-lo e mantê-lo na pureza. Essa lhe dá a certeza "que tudo é governado pela inefável providência e justiça de Deus, e que a ninguém a morte pode acontecer injustamente" (Id. Ibidem). A morte não é temida pelo homem sábio, pois têm consciência da imortalidade da alma.

\section{Blucher}


Tanto mais e mais a alma conhece, pelo fato de progredir, a diferença entre uma alma pura e uma maculada, quanto mais teme que, abandonado o corpo, Deus a possa suportar manchada menos do que ela mesma possa suportar. Mas nada mais difícil que temer a morte e abster-se das ciladas deste mundo, como 0 pedem os próprios perigos. Contudo a alma é tão grande que pode levar avante essas medidas com a ajuda da justiça do sumo e verdadeiro Deus, com a qual ele conserva e governa este mundo. Com a mesma justiça faz também com que não somente existam as coisas, mas existam de tal modo que não pode haver nada melhor. A ele a alma se entrega com piedade e confiança para ser ajudada e aperfeiçoada nessa tão difícil tarefa de sua purificação. (AGOSTINHO, 2008, p 342-3).

A alma provoca um movimento para além da realidade física ou material que a circunda. Em relação a si, perscruta a incorporeidade de sua forma, isto é, toma consciência de seu poder de transcendência. Olha para dentro de si e percebe sua insuficiência diante de Deus. A alma está no mundo, dele não se separou e aqui despende esforços para alcançar o conhecimento pleno de si. Nesse movimento se reconhece como pecadora e anela purificar-se. Reconhece seus erros e se distancia das coisas que a distanciam de seu Senhor e se aproxima da purificação.

Purificada, conseguiu parte de seu objetivo, no conhecimento reconhece sua grandeza. No ato anterior, estava no processo de purificação, agora, no quinto grau, já a alcançou. Não mais se deixa levar por impulsos e desejos, não se permite manchar porque liberta das paixões tende somente ao conhecimento de Deus. 
Depois de isto realizar, ou seja, quando a alma se libertar de toda imperfeição e estiver limpa de todas as manchas, então, finalmente, se mantém alegremente em si mesma e nada teme absolutamente para si e não se angustia por nenhum motivo. Portanto, este é o quinto grau. Uma coisa, porém, é realizar a purificação, e outra, manter-se na pureza; e uma é a ação com a qual se renova, estando manchada, e outra, a ação pela qual não consente em se manchar novamente. Neste grau ela percebe sob todos os aspectos o quanto é grande. Quando a percebe, então se dirige para Deus com confiança de certo modo imensa e incrível, ou seja, para a contemplação da verdade e para aquele altíssimo e deveras misterioso prêmio para o qual tanto se esforçou. (AGOSTINHO, 2008, p 343)

Movimentando em torno de si, a alma procura manter-se pura. As paixões silenciaramse, pois a alma desapegou-se delas, porém continua inquieta. 0 estado de pureza não lhe outorga a mais plena felicidade senão tranquilidade. Serena e consciente de sua grandeza, com confiança inquebrantável em Deus se dirige a Ele a fim de gozar os benefícios da contemplação da verdade. Apesar do quinto grau de atividade proporcionar à alma a pureza, essa não é suficiente para alcançar o gozo da paz e do amor vivenciados e encontrados somente em Deus. A alma precisa ascender ao próximo ato, como nesse grau se purificou, está limpa para seu triunfal encontro.

Dirigir-se a Deus é desejar entender o que é verdadeiro. Esse ato é o que há de mais sublime na alma, é o próprio movimento de ascensão. A alma transcende sua humanidade para estar com o divino, ou seja, volta-se completamente para Deus. Agostinho considera essa ascensão como sendo a sexta atividade da alma, a mais virtuosa e perfeita,

pois uma coisa é purificar o próprio olhar da alma para que não olhe inútil e temerariamente e enxergue o mal, outra coisa é preservar e fortalecer sua

\section{Blucher}


saúde, e outra coisa ainda é dirigir o olhar sereno e firme ao que pode ser visto. Com efeito, os que querem fazê-lo antes de serem purificados e se tornarem limpos, são de tal modo repelidos por essa luz da verdade, que não somente pensem que nela não existe nenhum bem, mas que envolve muito mal e the neguem o nome de verdade, e se refugiem com certa paixão e lascivo prazer em suas trevas, as quais sua enfermidade pode tolerar, maldizendo o remédio. [...]. Com efeito, conforme creio, é reto o Espírito que possibilita à alma não se deixar desviar nem errar na procura da verdade. Ele, sem dúvida não se renova na verdade, se antes não purificar o coração, ou seja, se antes o pensamento não se reprimir de toda paixão e sordidez e delas se purificar. (AGOSTINHO, 2008, p 343)

A alma, por estar convencida de sua conversão, de que será feliz somente quando se encontrar com Deus, se mantém limpa, pois somente assim estará apta a adentrar nos átrios daquele que the concedeu graça. Contudo, não se trata mais de manter-se apenas limpa, mas de lançar o olhar para aquilo que em certa medida já viu, mas que ainda não perscrutou, isto é, seu Criador. 0 sexto grau é o do entendimento de Deus, "prêmio misterioso" concedido àqueles que contínua e insistentemente cuidaram para se tornarem purificados e limpos. A alma purificada, que se reconhece como criatura divina não desvia do caminho percorrido, pelo contrário, se mantém na direção do Criador com humildade e amor para encontra-lo e com ele desfrutar da plenitude da vida e da Verdade divina.

Diante de Deus, após ter percorrido os seis graus, a alma alcança o seu objetivo, ou seja, atinge o conhecimento de Deus; não Ihe falta mais nada, está tranquila, em paz e feliz por ter encontrado seu Criador. Aquele que o impulsionou no caminho da verdade pela sabedoria e 
virtude é o próprio fim desse caminho. Assim sendo, o sétimo ato da alma não é um grau, é 0 estado de contemplação, de repouso da alma, aonde se chega por meio dos demais graus.

Deus é Causa e Autor, esse é o mais alto entendimento ao qual a razão humana pode chegar. A compreensão do mundo, da realidade e da vida é apenas ilusão ou filosofia vã se a alma não inteligir Deus. Esse é o caminho o qual, segundo Agostinho, Deus nos indica. A alma humana foi criada por Deus que a dotou de razão, e nisso se diferencia das demais, foi criada para entender grandes realidades, e não existe realidade maior e mais feliz do que Deus.

Contemplar Deus não significa paralisar-se diante Dele. Tendo chegado à contemplação é louvável e caridoso repartir conhecimento tão grande com as demais almas. A contemplação fazse comunicação, pois "do que há em abundância no coração, disso fala a boca" (MATEUS. 12, 34b.), a alma está repleta do amor divino e por isso além de conhecer e contemplar levará aos demais 0 amor e a verdade que são encontradas em um único ser: Deus.

Na visão e contemplação da verdade, que é o sétimo e último grau da alma, 0 qual não é certamente grau, mas certa mansão aonde se chega pelos outros graus, como dizer qual seja a alegria, o gozo do sumo e verdadeiro bem de cuja serenidade e eternidade é o sopro? [...] Mas é tão grande o prazer na contemplação da verdade, seja qual for 0 aspecto sobre o qual cada um pode contemplar; é tanta a pureza, tanta a sinceridade, tamanha fé inquebrantável nas coisas, que ninguém pense ter conhecido algo depois disto, se lhe parecia saber. E para que a alma toda não seja impedida de aderir a toda verdade, desejaria como a maior recompensa a morte que antes temia, ou seja, a fuga e a evasão deste corpo. (AGOSTINHO, 2008, p 344-6)

\section{Blucher}


Agostinho exorta a alma para que permaneça na posição que conquistou, a de contemplar a Verdade. Diante do Criador não teme mais a morte, antes deseja se separar do corpo para não ser "impedida de aderir a toda verdade" (Id. Ibidem)), Deus.

Apesar do longo caminho e esforço, a alma está tranquila, deleita-se em Deus, teve seu encontro com Ele, voltou-se para seu íntimo, para dentro de si, único lugar que pode contemplar Aquele a quem almejou conhecer.

\section{Bibliografia:}

AgOSTINHO. A grandeza da alma. Trad. Agustinho Belmonte. São Paulo: Paulus, 2008, 253-351 p. (Col. Patrística; Vol. 24)

. Sobre a potencialidade da alma (De quantitate animae). Trad. Aloysio Jansen de Faria, $2^{\mathrm{a}}$ ed. Petrópolis, RJ: Ed. Vozes, 2005, 187 p.

. Confissões. Trad. Arnaldo do Espírito Santo, et. al. $2^{\text {a }}$ ed. Lisboa:

Imprensa Nacional-Casa da Moeda, 2004, 779 p.

. Confissões. Trad. J. Oliveira Santos, et. al. São Paulo: Abril Cultural,

1973, 9-316 p. (Col. Os pensadores).

. Solilóquios. Trad. Adaury Fiorotti, $3^{\text {a }}$ ed. São Paulo: Paulus, 2007, 9-

108 p. (Col. Patrística; Vol. 11)

. A Trindade (De Trinitate). Trad. Arnaldo do Espírito Santo, et. al. São

Paulo: Paulinas, 2007, 1201 p.

A ordem. Trad. Frei Agustinho Belmonte. São Paulo: Paulus, 2008,

149-252 p. (Col. Patrística; Vol. 24)

AgOSTINO. Sull' anima (L'immortalità dell' anima. La grandezza dell' anima) 
Tradução de Giovanni Catapano. Milano: Bompiani, 2003, 448 p.

SANT'AgOSTINO. La grandezza dell'anima. Tradução de Paola Pascucci. Roma: Città Nuova. 2009, $294 \mathrm{p}$.

BÍBLIA SAGRADA. N. T. Mateus. São Paulo: Imprensa Bíblica Brasileira, 1997. Cap.12, p. 10.

CHAUÍ, Marilena. Introdução à História da Filosofia: Dos pré-socráticos a Aristóteles.

São Paulo: Brasiliense, 1994, 390 p. (Volume I). 